\title{
Multiculturalismo e o debate entre liberais e comunitaristas: em defesa da interculturalidade dos direitos humanos
}

\author{
Doglas Cesar Lucas ${ }^{1}$
}

\begin{abstract}
Sumário: Introdução; 1. Multiculturalismo: diferenças em busca de reconhecimento; 2. A posição liberal sobre a universalidade dos direitos humanos; 3. A posição comunitarista: na defesa dos direitos culturais; 4. O culturalismo liberal de Kymlicka e Raz; 5. Em defesa da interculturalidade dos Direitos humanos: sobre a necessidade de se superar o debate entre liberais e comunitaristas; Conclusão. Referências.
\end{abstract}

\begin{abstract}
Resumo: O presente texto pretende tratar da universalidade dos direitos humanos no âmbito da sociedade multicultural. Demonstra as diferentes posições que assumem os liberais e os comunitarisas no enfrentamento dos problemas de igualdade e de diferença que caracterizam as demandas de identidade e de pertença cultural. Refere que os direitos humanos são patrimônio comum da humanidade, e que sua universalidade mediadora/moderada é indispensável para a construção de um diálogo intercultural e para a elaboração de propostas de emancipação social que evitem tendências universalistas que homogeneízam e que combatam a desigualdade opressora travestida de direito a diferença.
\end{abstract}

Palavras-chave: Direitos humanos; liberalismo; comunitarismo; interculturalidade.

\begin{abstract}
This text aims to deal with the universality of human rights within a multicultural society. It shows the different positions that are adopted by liberals and communitarians when facing the problems of equality and difference that characterize the demands of cultural identity and belonging. It refers that human rights are a common heritage of mankind, and that its mediator/ moderate universality is essential the creation of an intercultural dialogue and to the drafting of social emancipation that avoids universalist tendencies that realize homogeneity and fight the oppressive inequality that intents to be a right to difference.
\end{abstract}

Keywords: Human rights; liberalism; communitarianism; interculturality.

1 Doutor em Direito pela UNISINOS e Mestre em Direito pela UFSC. Professor do Curso de Graduação em Direito e do Mestrado em Desenvolvimento na Universidade Regional do Noroeste do Estado do Rio Grande do Sul (UNIJUÍ). Professor do Curso de Gradução em Direito no Instituto Cenecista de Ensino Superior de Santo Ângelo (IESA). 


\section{Introdução}

Apesar de nunca ter saído de cena, o problema teórico e prático dos direitos humanos adquire uma peculiar importância no contexto da sociedade global. Novas formas de produção da sociabilidade dão visibilidade aos problemas que já existiam, mas que estavam encobertos ou atenuados pelas cortinas conceituais modernas e pela limitação real dos Estados-nação em responder aos desafios de um cenário político, econômico e cultural cada vez mais complexo. Os homens e suas respostas permanecem vinculados aos Estados nacionais, enquanto os problemas que pontuam os Direitos Humanos ganham escala mundial. Isso equivale dizer que as ações e os riscos globais são acompanhados, precariamente, apenas por respostas nacionais e particularistas, por respostas cada vez mais insuficientes, apesar, é preciso reconhecer, de crescerem as tentativas teóricas e políticas de se delinear respostas cosmopolitas.

Em uma sociedade que se complexifica, que reconstitui suas modalidades de produção de identidade e de pertença e que promove um permanente encontro entre culturas diversas, é inevitável que se estabeleça um dialético enfrentamento entre um projeto universal de Direitos Humanos e as múltiplas realidades culturais. Não que o problema do multiculturalismo seja um problema novo. É apenas uma realidade que se percebeu de forma mais substancial com o processo global de produção, operado a um só tempo, da sociabilidade e da barbárie. Afinal, os problemas somente são reconhecidos como tais quando nos damos conta de sua existência. A globalização provoca justamente este fenômeno de radicalização da visibilidade identitária, de aproximações e de afastamentos, de centralizações e descentralizações, de valorização do local e do global a um só tempo. As culturas locais ganham importância no processo de produção de identidade em um mundo que processa ondas de homogeneização. Nesse sentido, é importante evitar que o pluralismo cultural ou mesmo o universalismo uniformizador justifiquem denegações e construam novos fundamentalismos, capazes de fragilizar a capacidade emancipadora dos Direitos Humanos pelos relativismos produtores e defensores de qualquer tipo de sociabilidade.

Tendo presente a importância dos Direitos Humanos para a definição de uma cultura histórica comprometida com a paz e com a dignidade do homem, o presente texto tem a pretensão de apresentar, sem muitos 
detalhes, a defesa da interculturalidade como condição de possibilidade para a universalidade dos direitos humanos. Para tanto, o primeiro momento será dedicado à ideia, defendida pelo autor, de que os direitos humanos, junto com a democracia, compõem o conteúdo daquilo que ele denomina moral jurídica, capaz de obrigar mutuamente os indivíduos e as instituições a respeitarem essa mesma moralidade. No segundo e último item, defende-se a ideia de que, em uma sociedade multicultural, os Direitos Humanos constituem o limite ético para se realizar o diálogo entre as diferentes culturas, o limite para se estabelecer o diálogo dialético entre igualdade e diferença, entre universalismo e particularismo. Enfim, referese que os direitos humanos são patrimônio comum da humanidade e que a sua universalidade mediadora (mas não planificadora) é indispensável para a promoção de um diálogo intercultural e para a elaboração de propostas cosmopolitas de emancipação social.

\section{Multiculturalismo: diferenças em busca de reconhecimento}

Segundo Bhikhu Parekh (2000), as sociedades multiculturais modernas se diferenciam das sociedades multiculturais pré-modernas em quatro aspectos. Primeiro, porque nas sociedades pré-modernas as comunidades minoritárias mantinham-se reclusas nos exatos limites definidos pelos grupos dominantes, aceitando uma posição de subordinação. Nas sociedades modernas - melhor seria se dissesse "contemporâneas" -, a aproximação entre as culturas, resultado da dinâmica do processo de globalização, é praticamente inevitável, e graças aos ideários democráticos e liberais, mesmo as comunidades culturais ditas inferiores passaram a exigir igual direito de reconhecimento e participação. A segunda distinção mencionada pelo autor é tributada ao melhor entendimento que as sociedades modernas possuem em relação aos males que o dogmatismo moral pode provocar. Para o autor, a importância da cultura na formação do sujeito foi assimilada pela sociedade, que passou a respeitar as diferenças culturais e considerar a cultura como uma categoria política relevante. Como terceiro aspecto, é apresentada a nova conformação mundial no campo econômico, cultural e tecnológico, que tem ampliado o contato entre todas as partes do mundo e acabado por completo com o isolamento das culturas. Por fim, o autor 
refere como uma característica marcante das sociedades multiculturais contemporâneas as transformações que têm afetado o Estado-nação culturalmente homogeneizador.

Ainda de acordo com Parekh, o multiculturalismo, enquanto processo de reivindicação identitária, iniciou-se por volta de 1960, quando foi reconhecido pela mídia mundial o movimento popular norteamericano denominado "Panteras Negras". Esse movimento exigia o reconhecimento da situação peculiar das minorias de afrodescendentes nos Estados Unidos da América, dado que a formação da população desse país, embora tendo envolvido a emigração em massa de contingentes oriundos de diversas partes do globo, nunca abandonou a necessidade de respeito a um sentimento maior de "americanismo", largamente reproduzido pelos meios de ensino e comunicação. O movimento apoiou-se nos próprios instrumentos político-democráticos desse Estado, que possibilitam a livre manifestação do pensamento, para exigir o respeito à condição de diferença dos cidadãos dessa etnia, que, em sua maioria, não contavam, como acontecia então com a elite europeizada, com instrumentos de acesso equânime a serviços públicos mais avançados, como as universidades. O movimento dos "Panteras Negras" logo foi seguido por outros de equivalente poder de captação, não menos conhecidos mundialmente, como o feminismo ou o movimento homossexual. Os movimentos multiculturalistas aumentaram com a queda do muro de Berlim, evento após o qual todas as sociedades do bloco comunista passaram a conviver com reclamações por respeito às diferenças, especialmente étnicas - e a questão da Bósnia talvez seja o mais sensível desses casos.

$\mathrm{O}$ que todos esses movimentos tinham em comum era a necessidade de reconhecimento de suas diferenças culturais. Não desejavam - salvo em casos bem pontuais - que as especificidades de sua própria cultura suplantassem definitivamente o ideal nacional já estabelecido, ou mesmo que seus membros fossem considerados apartados do cenário cultural do Estado-nação. Apenas desejavam ser reconhecidos dentro da nação à qual pertenciam, como portadores de características particulares que os diferenciavam da população ainda adstrita à ideia de cidadania nacional. De fato, quando o Estado identifica todos os indivíduos sob o pálio da cidadania nacional, ignora as diferenças políticas, sociais e econômicas que afetam a manifestação de sua vida material. A igualdade jurídicopolítica dos cidadãos impede ao Estado considerar os cidadãos de forma 
especial, como portadores de características diferenciadas, nem piores, nem melhores - ou pior, faz até mesmo esquecer que tais diferenças existem. Essa "nivelação por baixo", fundada na ausência de políticas efetivas de promoção de um espaço público de aceitação e convivência entre as particularidades, faz com que se percam potencialidades individuais e coletivas, agindo justamente em desfavor da necessidade de preservação daquilo que é capaz de produzir a identidade e o sentimento de pertença (SEMPRINI, 1999).

Para Semprini (1999) o multiculturalismo revela os paradoxos da contemporaneidade, especialmente ao exigir que seus postulados de universalidade, de igualdade e de justiça sejam estendidos para todas as formas de manifestação cultural. A democracia moderna, calcada na ideia de sujeitos universais e na negação das identidades particulares, é desafiada pelo multiculturalismo na medida em que suas reivindicações têm em vista direitos que parecem dificilmente universalizáveis. Do ponto de vista do direito à diferença, conclamado pelo multiculturalismo, os ideais humanos universais seriam uma nova tentativa de homogeneização, tal como já verificado anteriormente com o processo de nacionalização do ente cultural. O conflito, então, se estabelece entre a necessidade de preservação das culturas dos diferentes povos e o dever de observância aos direitos do homem indistintamente entre esses grupos de indivíduos, enveredando, muitas vezes, para a relativização. Danilo Martuccelli (1996) refere que, com o multiculturalismo, a ideia de igualdade universal, que desconsiderava as diferenças, foi substituída pela concepção de equidade, caracterizada pelo reconhecimento das especificidades culturais dos indivíduos e dos grupos e pela possibilidade de um tratamento diferenciado para os membros dessas mesmas coletividades. Do mesmo modo, continua o autor, com o multiculturalismo, surge, da fusão entre liberdade negativa e liberdade positiva, a ideia de diferença como um direito individual de identidade, de autenticidade, de pertença a um grupo.

Por certo que a pluralidade cultural é uma realidade e uma virtude das sociedades democráticas que devem ser estimuladas. Por outro lado, o facilitado encontro das diferenças na sociedade global expôs, também, divergências e irritações que não favorecem o diálogo intercultural e que, não raras vezes, demarcam com agressividade o nível das oposições e afastamentos (OLIVÉ, 1999). Por isso, pode-se dizer que as demandas por reconhecimento das identidades culturais desafiam duplamente os direitos 
humanos, pois, ao mesmo tempo em que são requisitados para garantir o direito de cada cultura particular manifestar sua concreta historicidade e desenvolver seus laços identitários, os direitos humanos, por outro lado, são considerados como exigências recíprocas de abrangência universalista, que não condicionam seus fundamentos e sua validade a nenhuma experiência cultural específica. Assim, o fato de diferentes culturas postularem o mesmo direito de exercerem, num mesmo país, as suas diferenças, exige dos direitos humanos uma espécie de mediação entre a igualdade e a diferença que sua universalidade comporta (ALCALÁ, 2005; TORRE, 2000).

\section{A posição liberal sobre a universalidade dos direitos humanos}

O enfrentamento dos problemas culturais pela postura liberal não produziu uma teoria hermética a respeito do tema. São encontradas posições liberais mais abertas, outras mais fechadas, mas todas conduzem sua análise a partir de pressupostos que podem ser agrupados em único formato de abordagem. Sustentam os liberais que uma sociedade marcada por diferentes valores e por individualidades em conflito será mais bem ordenada quando todas as concepções de bem forem igualmente consideradas e quando nenhuma delas se sobrepuser às demais. Uma sociedade, aduz Rawls (2000) - depois de sofrer críticas comunitaristas ao conceito de pessoa abstrata e do véu da ignorância -, diferentemente de uma comunidade ou associação (que tem uma estrutura fechada e é autossuficiente, como é o caso da vida religiosa), não apresenta fins e objetivos predeterminados no que tange à eleição material de uma determinada concepção de bem, senão que compartilha de um objetivo comum no que se refere à definição de uma justiça política que consiga promover a cooperação social entre todos os cidadãos, inclusive de gerações diferentes, pela adoção de procedimentos e de instituições justas e pela valorização de todos os cidadãos como pessoas iguais e livres. (ALTABLE, 1995).

Uma característica determinante do entendimento liberal é o papel de centralidade atribuído ao indivíduo na formação da sociedade. A qualidade da pessoa, de sua autonomia, é anterior a qualquer fim. O homem é prévio 
a todo tipo de experiência histórica, não dependendo sua moralidade de vinculações de cunho social, político ou religioso (LA FUENTE, 2005). O homem tem sua dignidade amparada na sua natureza moral, na humanidade que lhe é inerente. Os vínculos identitários que possa estabelecer ao longo de sua vida não são determinantes e contingentes para a definição do que o homem é enquanto sujeito moral que deve ser protegido. O ser humano é um ser moral dotado de sentimento de justiça e capaz de estabelecer seus projetos de vida de modo autônomo, uma vez que pode atuar de acordo com princípios universais, com os quais os homens estariam de acordo como seres racionais, livres e iguais. Em outras palavras, o homem pode racionalmente fazer julgamentos morais que não decorrem de uma pauta específica de valores, mas de princípios universais que são reconhecidos para além de conceitos históricos, econômicos, culturais, religiosos, etc. (BICK, 1995).

Isso não quer dizer que o liberalismo se oponha à pluralidade de formas de vida. Antes, pelo contrário, reconhece que todos os homens, livres e iguais, devem conduzir seus projetos de vida levando em conta as suas inclinações e respeitando o mesmo direito para todos os outros homens. Os direitos, nesse sentido, servem para garantir a todos os homens o exercício de sua liberdade, de sua autonomia. São direitos do indivíduo como tal, que não podem ser afastados ou mitigados para preservar ou proteger a especificidade de uma cultura ou religião, por exemplo. Os direitos são essenciais aos indivíduos como seres humanos, não importando os vínculos que eles possam ter, e estão sustentados em sua autonomia moral. Os indivíduos possuem esses direitos, qualquer que seja a situação social, política ou religiosa em que conduzam sua existência. "Son universales en cuanto a su origen e idealmente universales en cuanto a su aplicación" (BICK, 1995, p. 82).

Quando o liberalismo estabelece uma prioridade do justo sobre as concepções de bem, é inevitável que tenha que reconhecer também a neutralidade do Estado sobre as concepções de bem de seus cidadãos. A esfera pública, nesse caso, não pode se imiscuir nas deliberações privadas dos indivíduos. O Estado deve assegurar a todos os cidadãos iguais oportunidades para promover as concepções de bem livremente formuladas, desde que, segundo Rawls (2000), estejam de acordo com os princípios de justiça. Da mesma forma, o Estado deve abster-se de estimular uma determinada concepção de bem em detrimento de outras, 
sendo desaconselhável reconhecer condições específicas para que um tipo de noção de bem se realize de forma mais favorável. Por isso, o Estado não deve interferir demasiadamente na vida de seus cidadãos, senão para garantir os meios necessários para que cada um possa realizar de forma satisfatória seus projetos pessoais de vida (VITALE, 2000; OLSEN, 2004).

Naturalmente, nenhum laço ou vínculo indentitário pode exercer um papel de protagonista na definição do bem de cada indivíduo, a ponto de exigir dele um respeito incondicional e o reconhecimento para além dos seus direitos individuais. Não cabem nas leituras liberais, notadamente nas mais fechadas, as demandas das minorias culturais exigindo a titularidade coletiva de direitos. Não é a cultura em si mesma que deve ser protegida, mas os direitos que todos os seres humanos possuem de se vincularem livremente a uma cultura ou de abandoná-la. Ao proteger o indivíduo moralmente considerado, o liberalismo propõe uma agenda universal de valores que se opõe a qualquer tipo de ataque organicista, seja estatal ou comunitário. Nesse sentido, o liberalismo se coloca de forma antagônica às pretensões particularistas que povoam as exigências da versão comunitarista do multiculturalismo (RUIZ, 2005).

\section{A posição comunitarista: na defesa dos direitos culturais}

Não obstante a especificidade presente nos diferentes autores comunitaristas, pode-se afirmar que todos eles convergem na direção de uma crítica ao liberalismo, a ponto de esta crítica ser ela mesma o fio convergente dessa corrente teórica. Reprovam a tese liberal que sustenta a noção de sociedade como um agrupamento de indivíduos, cada qual com sua concepção de vida boa, que são movidos por interesses e objetivos individuais e que possuem direitos que se sobrepõem e têm prioridade total diante de qualquer tipo de demanda comunitária. Para os comunitaristas e isso está bem caracterizado em Taylor (2000) -, defender a tese liberal é olvidar que os laços de pertença com a comunidade é que dão sentido à vida do indivíduo, uma vez que é pela relação dialogal, realizada na comunidade com os outros semelhantes, que a identidade cultural é forjada e que os vínculos de lealdade para com o grupo se tornam compreensíveis e indispensáveis para a reciprocidade, para a manutenção 
da própria comunidade e, consequentemente, para a consciência de si enquanto sujeito dependente de cultura (PINILLA, 1997).

Com efeito, os comunitaristas discordam do conceito de pessoa elaborado pelo liberalismo igualitário, pois alegam que, na definição do sujeito abstrato de direitos, não são consideradas as condições sociais nas quais este mesmo sujeito exerce sua capacidade de autodeterminação que o caracteriza enquanto sujeito moderno (MIGUEL, 1992). O sujeito moral dos liberais seria artificial, desconectado da realidade social. Da mesma forma, o comunitarismo não aceita a tese liberal que reconhece o indivíduo enquanto tal, independentemente do vínculo cultural, religioso, ou outra ligação de pertença, como sujeito capaz de questionar e de definir, por si só, os fins de sua relação com o mundo, a ponto de, inclusive, avaliar a possibilidade de continuar ou não a pertencer a uma determinada comunidade. Para os comunitaristas, os valores de uma comunidade não são eleitos isoladamente pelo indivíduo, mas são descobertos e reconhecidos durante o processo de pertencimento que se desenvolve em um grupo social. A identidade é anterior à escolha dos fins, aduz Sandel (2005). É a comunidade que tem prioridade sobre o indivíduo, pois é somente nela e a partir de suas valorações que o homem pode ter uma identidade; tão-somente por ela o homem é capaz de compreender que os seus valores são decorrentes das relações comunitárias e que a proteção de ditos valores é, também, a proteção de sua identidade pessoal (SANCHÉS-CÁMARA, 1998).

Apesar do próprio Macintyre (2001) afirmar que se distancia do comunitarismo, sob o argumento de que não está oferecendo um remédio para os males da sociedade como um todo, é evidente que nas suas críticas ao liberalismo está manifesta a importância da comunidade na definição das pautas morais (DÍAZ, 2001). De acordo com o autor, somente inserido no contexto social, cultural e histórico, o homem se define, cumpre seu papel, seu telos. Ser homem é cumprir com determinados papéis, cada qual com propósito específico. Por isso, a pertença a uma comunidade é requisito indispensável para toda a ideia de bem, uma vez que as virtudes se encontram vinculadas às atividades humanas cooperativas, estabelecidas socialmente mediante a realização dos bens que lhe são inerentes. Os juízos morais são juízos fáticos, pois as regras de moralidade somente fazem sentido em razão da específica maneira como o homem vive sua própria história; os dados de uma vida, 
as particularidades morais engendradas pela família, bairro, cidade, tribo, país, etc., produzem o ponto de partida para a descoberta da identidade moral. É importante notar, porém, segundo Ignácio Sanchéz-Cámara (1998), que Macintyre não está preocupado em impor o comunitarismo ao Estado, como tampouco apostar em um tipo de modelo comunitário, senão que pretende recuperá-lo nas instâncias coletivas menores, como na universidade, na igreja e em outras "aldeias".

O homem não pode eleger um bem se não tiver identidade e não pode ter identidade sem pertencer a uma comunidade; logo, não pode eleger uma noção de bem fora da comunidade (DÍAZ, 2001). Desse modo, não é possível conhecimento e avaliação ética fora dos próprios marcos de moralidade de cada comunidade (MASSINI CORREAS). A fonte exclusiva de moralidade são as tradições e os hábitos sociais aos quais está vinculado o sujeito, restando prejudicada a formação de conceitos universais de justiça e de moral. Por isso, afirma Macintyre, nenhuma teoria foi capaz de fundamentar os direitos humanos racionalmente, pois tais direitos não passam de ficções que fracassam ao submetê-los a um critério moral objetivo e impessoal. Uma vez que a incomensurabilidade moral é fruto de um contexto histórico particular e não de uma moralidade universal, acreditar nos direitos humanos como direitos da pessoa enquanto tal, como diziam os filósofos do século XVIII, é o "mesmo que acreditar em bruxas e unicórnios” (MACINTYRE, 2001, p. 127).

Também não é aceita pelos comunitaristas a tese liberal de que o Estado deve agir de forma neutra diante das diferentes concepções de bem existentes em uma dada comunidade, garantindo igual tratamento para todas elas e evitando a sobreposição de uma concepção específica de bem. Aduzem que é um equívoco defender a neutralidade do Estado, pois não é possível escapar-se de todos os efeitos do condicionamento ao qual está submetido. É uma ilusão liberal que tenta negar o que não pode ser negado: todas as organizações políticas estão sempre referenciadas por um conjunto de valores (SANDEL, 2005). Os pontos de partida liberal, diz Macintyre (2001, p. 371), "não são nunca neutros no que se refere às concepções do bem humano; eles são sempre pontos de partida liberais". Além do mais, essa pretendida neutralidade impede que se estabeleçam laços de solidariedade entre os membros de uma mesma coletividade, bem como mingua a possibilidade de se definir um bem comum a ser alcançado. A falta de um projeto compartilhado e a liberação moral dos 
indivíduos tornam o liberalismo uma tendência moralmente anêmica. Por isso, apregoam os comunitaristas que, em vez de se manter afastado, o Estado deve auxiliar os indivíduos a se identificarem com determinadas formas de vida comum; deve ser ativista e reconhecer direitos para as culturas coletivamente consideradas, como forma de garantir a sobrevivência das condições de possibilidade para o reconhecimento que se dá em razão direta com os vínculos de pertença mantidos com uma dada comunidade.

Inobstante o próprio Michael Walzer (2003) situar sua posição teórica no liberalismo, ele considera que o liberalismo precisa de uma periódica correção comunitarista. Preocupado em elaborar uma teoria de justiça distributiva, o autor, tendo como cenário a comunidade política, parte da noção de que a existência de diferentes bens em uma comunidade exige a conformação de distintas esferas de justiça, cada qual com seus princípios de distribuição, os quais são devidamente orientados de acordo com os bens que lhe são afeitos. Bens distintos são tratados por esferas distintas, respeitadas as particulares de cada comunidade e os princípios próprios de distribuição para cada tipo de bem. Tais diferenças resultam das inúmeras maneiras de se compreender os bens sociais, decorrência inerente à diversidade histórica e cultural. Com isso, o autor quer dizer que "os princípios da justiça são pluralistas na forma; que os diversos bens sociais devem ser distribuídos por motivos, segundo normas e por agentes diversos; e que toda essa diversidade provém das interpretações variadas dos próprios bens sociais - o inevitável produto do particularismo histórico e cultural" (WALZER, 2003, p. 5).

O valor dos bens decorre da comunidade, é um atributo que se desenvolve nas relações compartilhadas que diferem de grupo para grupo e de época para época. "Os significados sociais são históricos em caráter; portanto, as distribuições, e as distribuições justas e injustas, mudam com o tempo" (WALZER, 2003, p. 9). Cada cultura tem o seu entendimento sobre os bens sociais. Os homens produzem cultura e atribuem sentido compartilhado para as coisas, para os bens que valorizam. Desse modo, faz-se justiça quando são respeitadas as criações de cada particularidade, pois a justiça, antes de ser um conceito que valha universalmente, deve ser encontrada nas distintas experiências e locais que constituem o modo de vida compartilhado. Não existe, portanto, um conceito unívoco de justiça. Por isso, não existe uma distribuição absolutamente justa dos bens. 
Dependerão sempre, sua justiça ou injustiça, dos significados atribuídos aos bens a que se referem. Os critérios de justiça estão condicionados pela realidade social, pelos significados sociais elaborados para cada bem. Por essa razão, pode-se concluir que a diferença entre os homens não é necessariamente injusta em si mesma, mas, ao contrário, é natural. O que deve ser evitado não são as diferenças, mas o exercício do domínio, de um homem sobre outro, pela apropriação de um dado bem social. Portanto, defende Walzer, em vez da igualdade simples, de matiz distributiva, é preferível uma igualdade complexa, que supõe uma diversidade de critérios de distribuição, os quais refletem a diversidade de bens sociais existentes e a diversidade de compreensões particulares a seu respeito.

Ao tratar especificamente da questão multicultural, parece que Walzer (1998), apesar de não se afastar de todo da tese central do comunitarismo, acena para a possibilidade de uma escolha liberal não ser necessariamente contrária à proteção das particularidades culturais. $\mathrm{O}$ autor cita que existem, no argumento do próprio Taylor, duas tendências universalistas que orientam as democracias liberais para distintas direções políticas. Entre os dois tipos de liberalismo apresentados por Taylor, o primeiro tipo (Liberalismo 1) está comprometido com a defesa dos direitos individuais de forma neutra, sem proteger ou beneficiar nenhum projeto cultural ou religioso. O outro tipo de liberalismo, denominado por Walzer (1998, p. 121) de Liberalismo 2, "permite um Estado comprometido com a sobrevivência e o florescimento de uma determinada nação, cultura ou religião, ou com um grupo (limitado) de nações, culturas e religiões - desde que os direitos básicos dos cidadãos que têm diferentes compromissos ou que não têm nenhum estejam protegidos". Para Walzer, o multiculturalismo pode conviver com o liberalismo de um Estado neutral que, entretanto, reconheça a igualdade das diferentes culturas. Por isso ele manifesta sua preferência pelo liberalismo de tipo 1, desde que escolhido de dentro do liberalismo de tipo 2. Ou seja, a escolha não é dirigida por um compromisso com um Estado neutro e protetor dos direitos individuais, mas é "governada pela condição social e pelas escolhas de vida actuais destes homens e mulheres" (WALZER, 1998, p. 121).

A constatação da multiplicidade de tradições culturais serve de base para a crítica relativista da impossibilidade de uma formulação universal de direitos. Amparados em um ponto de vista antropológico, que considera a pluralidade cultural como um fato inegável da existência humana, 
postulam que, para além das diferenças, deve-se fazer um esforço para encontrar o ponto de convergência em que todas as culturas se conectam, o ponto de interculturalidade que é o único capaz de ser considerado universal. Dito de maneira mais específica, para os comunitaristas, a universalidade homogeneíza, acaba com as diferenças tão importantes que dão significado à vida de cada membro da comunidade; ela desconsidera os elementos reais de solidariedade e sustenta-se em uma ideia abstrata de sujeito que não existe em nenhum lugar (SORIANO, 2004). Os comunitaristas defendem que não é possível uma fundamentação universal dos direitos humanos, razão pela qual, não sendo possível identificar laços de aproximação entre os direitos universais e as culturas específicas, não haveria necessidade de reconhecê-los.

\section{O culturalismo liberal de Kymlicka e Raz}

Will Kymlicka (1996) defende a construção compartilhada entre as posturas liberais e comunitaristas, argumentando que a cultura é um espaço legítimo de produção de identidade que deve ser protegido pelo direito estatal, mas cujos limites não podem suplantar a afirmação individual do sujeito enquanto ente portador de liberdade. Parte do pressuposto de que as sociedades liberais do Ocidente não são suficientemente respeitosas no que tange à preservação dos direitos de auto-organização e representatividade das minorias, embora sejam as que mais proporcionem aos indivíduos oportunidades de vida livre e plena. Defende, portanto, a manutenção das liberdades individuais e a promoção dos direitos coletivos das minorias, de forma harmônica e coordenada.

Para ele, o conjunto de opções de vida de cada indivíduo seria condicionado pela cultura, esta enquanto berço do desenvolvimento individual consciente, uma base para a dedução das escolhas culturais do sujeito. A cultura teria o poder de moldar o indivíduo, influenciando fundamentalmente o exercício de sua autonomia pessoal, mas sem servir de alavanca a um determinismo social mecanizado, nem de barreira à expressão prática de modos de vida e à demonstração de potencialidades. $\mathrm{Na}$ teoria de Kymlicka, o nacionalismo coexistiria naturalmente com o liberalismo, sendo inclusive fundamental para o funcionamento das instituições democráticas liberais, mas sem ser agressivo o suficiente 
para impingir identidade nacional àqueles que não querem compartilhar desse pertencimento. O nacionalismo liberal de Kymlicka (2004) não teria vinculação com civismos ou etnicismos homogeneizantes, servindo apenas como base para a difusão de uma língua e de uma cultura nacional comuns, mas de forma inclusiva, aberta a acessões, possibilitando ao sujeito contextualizado decidir por seu próprio caminho por meio de escolhas livres.

O Estado, neste contexto, não poderia ficar alheio à manifestação das diferenças, em posição neutra, como se elas não existissem ou como se a vida concreta dos indivíduos não dependesse diretamente de seu reconhecimento. Deveria ele, por esta ótica, realizar uma série de necessárias escolhas culturais, visando justamente a manter o campo de diálogo entre as diversas fontes identitárias num espaço público de manifestação comum. Kymlica disserta que as minorias não podem ser compreendidas de forma genérica, como se representassem um grupo sólido e padronizado de alternativas à comunidade majoritária. Para ele, há diferentes tipos de minorias, que podem ser classificados conforme seja mais ou menos eficiente o fator de coesão de cada grupo. Por esta ótica, grupos de refugiados ou de imigrantes seriam minorias mais frágeis do que nações minoritárias - como os quebequenses canadenses ou os aborígines australianos - e, justamente por isso, demandariam políticas estatais mais precisas no tocante à preservação de seus interesses históricos (MALDONADO, 2006).

O intento de Kymlicka (2003) para projetar o discurso das diferentes formas de produção de identidade seria forçar a liberalização das culturas ortodoxas, pressupondo que as que hoje são consideradas mais abertas à compreensão das diferenças foram, outrora, tão iliberais quanto aquelas. Visa, com isso, à readequação da representatividade das diferentes culturas num espaço comum, ficando o liberalismo como parâmetro maior da aceitabilidade ou não de práticas iliberais das diferentes culturas comunitárias. Haveria de se exigir das minorias que aceitassem valores universais mínimos, entre os quais o direito de um indivíduo abandonar a comunidade de origem e o de resistir a determinadas práticas culturais, ficando o direito de a comunidade se utilizar de instrumentos para manter sua coesão interna sujeito ao exercício do direito individual à autodeterminação. Neste sentido, qualquer normatividade cultural que extirpasse a autonomia do indivíduo não deveria ser tolerada, sob pena de 
desrespeito à figura do homem enquanto ente universalmente considerado. As diferentes culturas deveriam aceitar concorrentemente as influências umas das outras, mesmo a fim de possibilitar o exercício da liberdade cultural pelo indivíduo isoladamente considerado, mas sem abandonar aquilo que as constituem enquanto manifestações coletivas capazes de sustentar sentimentos de pertença (COLOZZI, 2003).

Segundo Kymlicka (2003), a compreensão tradicional-liberalista dos direitos humanos não é capaz de reconhecer de forma justa a representatividade das minorias, pois se prende ainda à defesa de interesses eminentemente individuais, enquanto o mundo contemporâneo lida com reclamos cada vez mais pujantes no tocante ao reconhecimento de práticas culturais particulares. Para ele, os direitos humanos puramente individuais representam uma tentativa de europeização, na medida em que desconsideram a patente diversidade cultural da contemporaneidade em prol da massificação de um ideal histórico ocidental, contra o qual se manifestam concretamente diversas ondas de comunitarismo.

Seria necessária, assim, uma nova compreensão de direitos humanos, capaz de mesclar os direitos individuais tradicionais com direitos culturais coletivos, no intuito de proteger os indivíduos dentro e fora de seus grupos culturais, segundo uma gama de "direitos diferenciados em função dos grupos” (KYMLICKA, 1996, p. 46). O filósofo Canadense acredita que o reconhecimento dos direitos coletivos das minorias não representa uma limitação ou a retirada da importância dos direitos humanos individuais. Antes disso, estes seriam reforçados por aqueles no momento em que passassem a ser compreendidos como via fundamental de diálogo entre os integrantes de cada comunidade. Não deveria, para ele, haver uma separação saliente entre os direitos humanos individuais e coletivos, pois ambos se suportariam em relações de coordenação e complementaridade, convivendo de forma afinada. Ao final, tanto os direitos humanos individuais quanto os direitos humanos coletivos das minorias seriam necessários para a tessitura de uma ideia de dignidade humana objetiva, fundamental para a tomada de consciência sobre o significado da existência (SEOANE, 1998).

Assim como Kymlicka, Joseph Raz é defensor do multiculturalismo liberal ou do liberalismo culturalista. Sustenta que o liberalismo não é simplesmente uma moral política válida, mas sim aquela que melhor representa a noção do que é bom para todas as pessoas, ainda que por 
aproximação, já que considera não haver valor universal que sustente ante as fugazes, porém recorrentes e muito profundas, modificações do mundo contemporâneo. Para ele, a cultura é o espaço de produção da consciência individual, onde se estabelecem os parâmetros fundamentais do exercício da inventividade e da autonomia. Viver em comunidades culturais, assim, seria necessário tanto para facilitar o implemento das relações sociais e políticas quanto para produzir a identidade individual de forma legítima.

Raz (2001) considera que o multiculturalismo enquanto fenômeno social é ligado ao processo contínuo de aberturas político-econômicas da contemporaneidade, o qual é inclusive sustentado pelo liberalismo histórico. No entanto, por mais que este modelo político se fie às ideias de tolerância e não discriminação, seu enfoque burocratizado da singularidade, que impõe o anonimato e a neutralidade ante as diferenças, não é suficiente para pôr as minorias e as maiorias em pé de igualdade no espaço público de discussão de políticas comuns. O estabelecimento de espaços próprios para a manifestação de cada cultura seria uma necessidade, até porque seria injusto - ou, para ser mais fiel às ideias do autor, iliberal - exigir que uma cultura seja suplantada por outra por ser considerada "menos importante". Deveria haver entre elas uma tolerância mínima, fortalecida pelo "direito de saída" (RAZ, 2001, p. 196) do indivíduo de sua comunidade cultural em caso de não pactuação com determinadas práticas ofensivas.

Para Raz, o multiculturalismo só é viável enquanto instrumento ético de proteção das diferenças, e não como política de preservação de práticas culturais "fossilizadas", que contrariam diretamente os valores mínimos tidos como universais. Nesses casos, tais culturas deveriam ser suplantadas por práticas liberais mais comprometidas com as garantias de liberdades individuais. De mais a mais, a convivência das diferentes manifestações comunais no espaço multicultural importa em um processo contínuo de agregação e assimilação, o qual só será saudável e aceitável enquanto não for imposto pela maioria privilegiada nem desrespeitar os integrantes dos grupos culturais menos expressivos. $\mathrm{O}$ que se deveria disseminar, ao final, segundo o autor, seria uma cultura política comum, que possibilitasse a todos o mesmo acesso às esferas de produção e reprodução do poder, sem falar em um limite ético mínimo para as manifestações culturais, a fim de erradicar práticas ofensivas à noção de dignidade humana universalmente considerada. 


\section{Em defesa da interculturalidade dos Direitos Humanos: sobre a necessidade de se superar o debate entre liberais e comunitaristas}

Se o mal do liberalismo é desconsiderar as peculiaridades históricas de cada comunidade no reconhecimento de direitos específicos, alimentando uma cultura individualista de baixa integração entre seus integrantes e eliminando as condições materiais de desenvolvimento da identidade de cada indivíduo, os perigos das alternativas comunitaristas para a universalidade dos direitos humanos também não devem ser desconsiderados. Encerradas em si mesmas, tendem para o isolamento, para a afirmação de políticas de exclusão do diferente e para a formação de reclamos sustentados em práticas xenofóbicas, em nome de uma coesão social construída por relações de poder - político e militar - que se configuram em uma espécie de ditadura comunitarista (TOURAINE, 1999; LAPORTA, 1995). Se a comunidade permite o acesso do homem ao mundo de significações, como alegam os comunitaristas, não é menos verdadeiro que é a humanidade comum do homem-marca que permite o diálogo intercultural, o diálogo entre diferenças que se reconhecem mutuamente a partir de traços comuns-que faz da comunidade um âmbito de manifestação das particularidades e das diferenças, que também marcam a ideia de universalidade da humanidade.

Ao que parece, o problema da universalidade dos direitos humanos na sociedade multicultural tem sido enfrentado por liberais e comunitaristas, cada um a seu modo, sem que se tenha explorado todas as possibilidades de não contradição entre particularismo, pluralismo, diversidade e universalidade (MARTÍNEZ-PUJALTE, 1998). De fato, a premissa básica dos direitos humanos, referenciada desde os jusnaturalistas, destaca que eles se constituem enquanto ideias-força, ou seja, se fortalecem quando são violados, não perdendo suas características mesmo quando negados com base em atos culturais. Assim, a construção de uma teoria justificadora que fundamente e situe os direitos humanos diante de sistemas e práticas morais diversas supõe a superação da dicotomia universalidade/diferença, universalismo/particularismo, na busca de valores compartilhados, de valores e de direitos humanos que situam sua validade na humanidade do homem como tal, independentemente de qualquer tipo de vínculo de pertença (ZACCARIA, 2003). 
Ao posicionar os sujeitos como pertences de uma mesma identidade, estabelecendo as bases de pertença para com o seu semelhante, a relação da cultura com o direito tende a ser inevitavelmente uma relação que demanda reconhecimento por sua diferença em relação às outras culturas, na intenção de satisfazer suas necessidades internas e de reproduzir seu modelo de identidade e, portanto, de diferença em relação aos outros. Com isso, todo o reclamo por identidade é, nesse caso, um reclamo por constituir os limites jurídicos que resguardam esta mesma diferença da interferência dos outros não semelhantes, a qual requer uma proteção especial. Nessas circunstâncias, querer não participar de uma comunidade, ou querer participar dela na condição de diferente - na verdade, é sempre na condição de diferente -, são interesses que poderão colidir e, por consequência, produzir soluções inevitavelmente excludentes e discriminatórias, as quais são inconcebíveis pela universalidade dos direitos humanos (SEOANE, 1998).

A tarefa dos direitos humanos, nesse cenário, é estabelecer os exatos limites da igualdade e da diferença entre os indivíduos e entre as culturas, sem contudo negar os aspectos comuns que os identificam na qualidade de sujeitos particulares. Numa sociedade multicultural, esse desafio configura-se ainda maior, pois, enquanto as múltiplas identidades culturais existentes em um país postulam o direito de manifestarem sua especificidade nas mesmas condições, os direitos humanos devem tutelar apenas as diferenças que não sufocam sua missão de garantir a todos os homens enquanto tais, e não como integrantes dessa ou daquela cultura, os direitos necessários ao exercício de sua liberdade e autonomia. Eis então a questão: É possível sustentar a legitimidade de toda e qualquer cultura sem esvaziar a virtude universalista dos direitos humanos? $\mathrm{Ou}, \mathrm{em}$ outras palavras, é possível defender a universalidade dos direitos humanos sem atacar toda a espécie de relativismo que nega a possibilidade de fundamentar tais direitos na humanidade comum de cada homem? Enfim, até que ponto universalidade e particularismo não se opõem?

A universalidade dos direitos humanos não tolera toda nem qualquer forma de particularidade cultural (RUIZ-GALVEZ, 1999 1997). Garantir o mesmo tratamento para as diferentes culturas e demandas identitárias, independentemente da substancialidade normativa e ética de cada uma delas, importa em defender de modo ilimitado a diferença e o particularismo, e mais, acabar com o papel crítico e propositivo dos 
direitos humanos. Se todo particularismo é considerado igualmente moral, se cada sociedade produz sua concepção válida de moral crítica, conceitos como violência, liberdade e solidariedade perdem toda a sua força referencial para uma análise universal desses temas. A universalidade dos direitos humanos, não custa lembrar, é de direito e não de fato e, portanto, suas exigências permanecem intactas mesmo quando na prática as comunidades particulares não os cumpram (CAMPS, 1996).

Por isso, se os direitos humanos não puderem ser apresentados como um conjunto de exigências recíprocas que se devem os homens e os Estados, independentemente de sua posição geográfica, econômica, política e também cultural, discursos e práticas ditatoriais, preconceitos de todas as ordens, costumes ofensivos à dignidade humana e outras ações aviltantes serão sempre legitimados pelas moralidades dominantes, moralidades locais, reproduzindo-se as realidades que os direitos humanos visam a enfrentar. A questão não é, como se disse, reconhecer e aceitar as diferenças culturais que traduzem as formas particulares de se produzir pertença digna no mundo. Tomada nesses termos, a diversidade se constitui como fonte de inventividade e de renovadas riquezas autênticas que merece proteção. O problema reside em práticas culturais que aviltam, que impõem um comportamento indesejado para uma parcela dessa mesma cultura, funcionando como mecanismo de poder e de autoridade hierárquica.

As lutas em prol das diferenças não podem ocorrer isolando-as cada vez mais do encontro com as igualdades e peculiaridades que marcam o outro da mesma ou diferente cultura. Nesse diálogo, não são as marcas que afastam que deveriam importar, mas são os pontos que convergem para uma humanidade comum, centrada na reciprocidade de exigências, que deverão compor a agenda de responsabilidades de todos. Ao desistirem de procurar o indivíduo como sujeito moral, os comunitaristas aumentaram o abismo entre as diferenças que, por exigirem reconhecimento específico, cumprem quase exclusivamente com o papel de construir a identidade do sujeito como membro de uma determinada coletividade. Não há, nas condições comunitaristas, espaço para a dignidade humana, mas apenas para uma dignidade da cultura, apresentada, então, como pré-condição da própria individualidade. Abusando da metáfora, é como se víssemos mais índio no homem que homem no índio; que judeu nos dissesse algo bem mais significativo que homem. Todos conhecemos o legado e os riscos 
das uniformizações que sufocaram a autonomia moral do sujeito em prol da cultura, religião, nacionalidade, raça, etc.

Mas o problema das diferenças também não foi plenamente respondido pelos liberais radicais ou mesmo pelo culturalismo liberal. Se no comunitarismo, o perigo é caracterizado pelo potencial isolamento das culturas entre si, nas tendências liberais a falta de solidariedade entre os indivíduos e a universalidade abstrata são apontadas como fragilidades substanciais para a condução satisfatória dos projetos de vida coletivos e para a proteção das minorias. Certamente que os direitos de um indivíduo necessitam de condições objetivas de efetivação, entre as quais o fator econômico se encontra em posição de destaque. Por isso, a dignidade e a liberdade dos indivíduos não serão automaticamente garantidas sem que exista um favorável cenário material para tanto, não bastando uma posição de neutralidade e de não intervenção por parte do Estado ou dos outros cidadãos. Ao retratarem o sujeito em uma condição de pura idealidade, as posições liberais correm o risco de reproduzir uma universalidade homogeneizadora, que desconsidera as diferenças importantes que constituem o homem em sua humanidade, seus vínculos sociais e sua existência material; que deixa de lado, segundo Juan Carlos Arroyo (2000), a dimensão supraindividual do ser humano, esquecendo-se que o próprio processo de individualização se perfaz por meio da socialização com outros sujeitos.

Não se trata, então, como já se afirmou, de defender uma universalidade uniformizadora ou um particularismo desigualizador (SOUSA, 2003). É na interculturalidade que os direitos humanos depositam sua fonte de legitimidade ética e sua força política. Ao mediar doses de comunitarismo no individualismo e vice-versa, o interculturalismo viabiliza a formação de novos consensos, de diálogos que contemplam a presença da riqueza da historicidade sem, contudo, sonegar a autonomia e a liberdade igual de todos os indivíduos (HABERMAS, 2002; APEL, 2000).

Para contrapor o relativismo à universalidade abstrata, Christoph Eberhard (2004, p. 167) sugere a adoção de um "pluralismo saudável", baseado em um "diálogo mútuo que permite que descubramos respectivamente aos outros e a nós mesmos, e que descubramos o passado e o presente de ambos, construindo juntos um futuro comum". Um 
diálogo intercultural sobre os direitos humanos, portanto, não pode ser interpretado como uma postura totalmente relativista, ou como negativa da universalidade ou da importância de tais direitos. Segundo o autor, “a questão não é desconstruir a abordagem ocidental refutando sua universalidade, mas sim enriquecê-la por meio de perspectivas culturais diferentes, com vistas a avançar progressivamente rumo a uma práxis intercultural dos direitos humanos e abrir novos horizontes para uma boa vida para todas as pessoas" (EBERHARD, 2004, p. 161). O diálogo entre as culturas permite a formação de novos horizontes e predispõe o homem a olhar e a escutar os outros, alterando suas concepções sobre o mundo, o que é condição indispensável para a coexistência pacífica. É preciso entender, de acordo com Montiel (2003, p. 43), que, da mesma forma que os antepassados "se adaptaram às circunstâncias do mundo que os rodeava, nós também deveremos abrir-nos às culturas de hoje. Somente através de um intercâmbio fluido teremos a possibilidade de encontrar novas soluções para nossas diferenças culturais". O encontro com as outras culturas tende a contribuir para a formação de projetos que se enriquecem mutuamente, bem como permite conhecer as virtudes presentes no outro e encontrar as semelhanças que permitem a definição de uma pauta comum de preocupações que será a base para as conversações (DOLORES, 1998).

Por isso, o diálogo intercultural é antes uma exigência ética do que geopolítica, pois sua agenda de preocupações está centrada na semelhança das demandas que perpassam todas as culturas, e não nas postulações setoriais de uma dada cultura em particular. Como uma reivindicação ética, o diálogo entre as culturas, anota acertadamente August Arazo (1992, p. 163), "comporta también la exclusión de todo fanatismo y autocomplacencia. [...] Se trata, en definitiva, de hacer posible una comunicación libre y sincera que conduzca a una acción solidaria y creativa. Solamente sobre tal base los derechos humanos pueden adquirir su sentido pleno". Assim, a interculturalidade deve ser entendida como uma alternativa para a coexistência das diferentes culturas, porque permite o reconhecimento do direito à diferença sem corroborar as práticas políticas assimilacionistas e de segregação e sem promover a perda dos elementos constituidores de cada cultura, permitindo que a união das semelhanças que brotam do diálogo entre as culturas e a formação de novos consensos contribuam para o surgimento de um novo modelo (CORELLA, 1998). 
O diálogo intercultural visa a identificar, nas diferentes culturas, os traços de humanidade que dizem respeito à existência digna do homem, independentemente da cultura, nação, religião ou outro vínculo. Assim, por exemplo, são considerados valores universais a dignidade humana, a identidade, a liberdade de ser e de estar, a inviolabilidade do corpo, o bemestar humano, entre outros. Isso, como já se disse, não implica a promoção de uma homogeneização das práticas culturais num universalismo abstrato que nega a diferença, mas a compreensão dos atributos humanos comuns que perpassam todas as existências individuais e que devem ser reconhecidos reciprocamente como necessários à convivência pacífica. A humanidade comum do homem não quer dizer que todas as culturas e sujeitos particulares estejam fadados a uma história comum, com conceitos, práticas, hábitos e mesmo valores uniformes. Obviamente isso não teria sentido, e a realidade bem demonstra isso. É sabido que existem características morais que dão o tom da humanidade comum presente em cada ser humano, as quais se manifestam de diferentes maneiras nas comunidades culturais particulares, que produzem, cada uma a seu modo, suas regras e seus conceitos. O homem, para além dos traços da espécie, também apresenta elementos comuns no que tange à sua dependência formativa da cultura e no que se refere a sua individualidade reflexiva. É essa humanidade comum, então, presente em cada um de nós e em cada manifestação cultural específica, que deve fomentar o diálogo entre as culturas e promover o reconhecimento intercultural de um conjunto de obrigações recíprocas que se devem os homens para poder coexistirem dignamente.

De fato, é preciso superar o multiculturalismo de justaposição, que inevitavelmente leva à construção de isolamento, de guetos étnicos que tendem a proliferar rivalidades. Numa sociedade em que as diferenças são cada vez mais aparentes e desafiadoras do consenso, não é de bom alvitre que as janelas de cada cultura se fechem e impeçam olhares de fora para dentro e de dentro para fora. Não devem ser tomadas como moralmente aceitáveis as alternativas comunitaristas que sufocam a autonomia e a liberdade do indivíduo na condução da vida segundo suas escolhas críticas, como também não são desejáveis as soluções liberais que aniquilam o indivíduo ao universalizá-lo abstratamente, ao retirá-lo do mundo real das influências e trocas culturais. Nesse sentido, o papel dos direitos humanos é permitir que todos os homens, em igualdade de condições, 
acessem o mundo com liberdade e dignidade, independentemente dos vínculos culturais que possuam. Sua missão, então, é promover um diálogo intercultural que fortaleça, em escala global, as demandas comuns do homem e as instituições democráticas para resolvê-las, facultando uma conversação na qual todos os interessados, culturas e indivíduos, possam, em igualdade de condições, manifestar as suas preocupações e as suas diferenças, na busca de respostas para os problemas que são interculturais.

\section{Conclusão}

Apesar da efetivação dos direitos humanos e mesmo sua definição material estarem diretamente vinculadas à realidade histórica de uma comunidade, isso não quer dizer que o fundamento desses direitos possa ser encontrado na história dessa mesma comunidade. Os direitos humanos não podem ser explicados e fundamentados em si mesmos, mas na universalidade que constitui o homem como tal. Assim como não se pode fundamentar o direito positivo em si mesmo, mas sim em interesses e valores de várias ordens, os direitos humanos pretendem retratar o que é universalmente indispensável ao homem, independentemente de sua identidade cultural. Antes de ter uma identidade cultural que lhe dá uma perspectiva de estar no mundo, uma identidade e uma pertença, o homem é refém de sua própria posição humana, que é universal, pressuposto para a afirmação de seus sentidos individuais e de grupo (FERNÁNDEZ, 2003).

Se a teoria dos direitos humanos cultivar e defender sectarismos e relativismos de qualquer ordem, os problemas do mundo não passarão de problemas de Estado ou de uma cultura, problemas objetivados na percepção pura e simples das necessidades básicas e circunstanciais de cada grupo isolado. Numa sociedade multicultural, permeada por diferentes identidades, os direitos humanos devem ser o referencial comum para um diálogo intercultural, capaz de aproximar as diferenças e de reconhecê-las em sua perspectiva histórica. Como se disse, não se trata de uma universalização uniformizadora, mas sim de uma "universalidade moderada", que poderá mediar as diferenças e servir de ponto de partida ético para uma cultura de tolerância e de emancipação que reconheça as 
identidades sem ofuscar e negar aquilo que é reclamado pela condição humana universal, por todos os povos e por todas as culturas.

Essa estratégia pelos direitos humanos é condição, inclusive, para a manutenção das próprias diferenças identitárias; caso contrário, a relativização de tudo e de qualquer valor poderá permitir o avanço de uma cultura particular sobre a outra. A prática nazista de igualização ou de indiferenciação humana, proposta de modo uniforme nos campos de concentração, por exemplo, retrata o perigo que pode representar o domínio de uma percepção histórica, o perigo que está demarcado em um relativismo uniformizador. Negar a diferença pode ser tão desastroso para a democracia como negar a universalidade da condição humana. A universalidade dos direitos humanos, nesse caso, antes de ser obstáculo, é condição para o desenvolvimento, reconhecimento e tolerância das identidades e das culturas que respeitam as outras culturas e que garantem para os seus integrantes o direito de exercerem sua individualidade autonomamente. $\mathrm{O}$ que se percebe, inclusive, é que a universalidade dos direitos humanos permite que sejam reconhecidas muitas culturas que seriam negadas se não existissem determinados direitos específicos que protegem certas diferenças. Assim, ao reconhecer a humanidade comum de todos os homens, as diferenças e os particularismos adquirem sentido pelo recurso aos direitos humanos, que identifica aquelas condições que não podem ser pluralizadas e tampouco legitimidades pelo argumento historicista (HÖFFE, 2000).

Um diálogo intercultural, nesse contexto, poderá representar uma abertura para processos de conhecimento recíproco que, mesmo que opere de modo tenso e conflituoso, produz encontros de diferenças e de igualdades que tendem a se reconhecer ou se rejeitar. Esse choque de estranhamento é inevitável quando se está diante do novo e do inusitado, na leitura de culturas diferentes. Por outro lado, é preciso ter clareza que interculturalidade não pode ser entendida como sendo a condição de possibilidade da formação de um acordo semântico em torno de conceitos, uma espécie de consenso fundante do diálogo. Interculturalidade deve ser tomada como um momento de alteridade, no qual as diferentes culturas se percebam, reconheçam-se e diferenciam-se tomando por base elementos comuns e compartidos entre elas. Em outras palavras, a diferença de uma cultura somente é percebida internamente pelos seus "eus" semelhantes quando em contato com os "outros" de culturas diferentes. Assim, o 
diálogo intercultural é indispensável para que as diferenças sobrevivam, mas sobretudo para que o diálogo entre a igualdade e diferença entre as culturas seja mediado por formas não arbitrárias e fundamentalistas de produzir a pertença e a identidade, como se os direitos humanos pudessem ser completamente subjugados pelo direito de as culturas distintas fazerem o que desejarem internamente contra o seus componentes. Por fim, é necessário ficar alerta para o risco, sempre presente, de a universalidade sem moderações converter-se em homogeneização ou de o direito à diferença propagar desigualdade. A interculturalidade dos direitos humanos tem substancialidade suficiente para desempenhar os limites mediadores entre a igualdade e a diferença e impedir a formação de novos fundamentalismos baseados na negação da igualdade e/ou na negação da diferença.

\section{Referências}

ALCALÁ, J. Alberto del Real. Problemas de gestión de la diversidad cultural en un mundo plural. In: RUIZ, Ramón et al. (Ed.). Derechos fundamentales, valores y multiculturalismo. Madrid: Dykinson, 2005.

ALTABLE, Maria Pilar González. Liberalismo vs. Comunitarismo (John Rawls: una concepción política del bien). In: Doxa. Cuadernos de Filosofía del Derecho. Alicante: Universidad de Alicante; Biblioteca Digital Miguel Cervantes, n. 17-18, p. 117-136, 1995.

ÁLVAREZ, Silvina. La racionalidad de la moral. Un análisis crítico de los presupuestos morales del comunitarismo. Madrid: Centro de Estudios Politicos y Constitucionales, 2002.

APEL, Karl-Otto. O problema do multiculturalismo à luz da ética do discurso. In: ETHICA-Cadernos Acadêmicos. v. 7. Rio de Janeiro, 2000.

ARAZO, August Monzon I. Derechos humanos y diálogo intercultural. In: BALLLESTEROS, Jesús (Ed.). Derechos humanos. Concepto, fundamentos, sujetos. Madrid: Editorial Tecnos, 1992.

ARROYO, Juan Carlos Velasco. Derechos de las minorías y democracia liberal: un debate abierto. In: Revista de Estudios Políticos. Madrid: Nueva Época. n. 109, Julio-Septiembre de 2000. 
BICK, Mimi. El debate entre liberales y comunitaristas. Santiago de Chile: Universidad Nacional Andrés Bello, 1995.

CAMPS, Victoria. La universalidad y sus enemigos. In: GINER, S.; SCARTEZZINI, R. (Ed.). Universalidad y diferencia. Madrid: Alianza Editorial, 1996.

COLOZZI, Ivo. Ciudadanía y bien común en la sociedad multiétnica y multicultural. In: Persona y Derecho. Pamplona: Universidad de Navarra, n. 49, 2003.

CORELLLA, Ángeles Solanes. Una respuesta al rechazo racista de la inmigración: La interculturalidad. In: Anuario de filosofía del derecho. Madrid: Nueva Época. Tomo XV, 1998.

DÍAZ, Francisco Javier de la Torre. El modelo de diálogo intercultural de Alasdair MacIntyre. El diálogo entre las diferentes tradiciones. Madrid: Dykinson, 2001.

DULCE, María José Fariñas. Los derechos humanos: desde la perspectiva sociológico-jurídica a la "actitud postmoderna". Madrid: Dykinson, 1997.

EBERHARD, Christoph. Direitos humanos e diálogo intercultural. Uma perspectiva antropológica. In: BALDI, César Augusto (Org.). Direitos humanos na sociedade cosmopolita. Rio de Janeiro: Renovar, 2004.

FERNÁNDEZ, Encarnación. Igualdad y derechos humanos. Madrid: Editorial Tecnos, 2003.

GREBLO, Edoardo. A misura del mondo. Globalizzazione, democracia, diritti. Bolognia: Il Mulino, 2004.

HABERMAS, Jürgen. A inclusão do outro. Estudos de teoria política. Tradução de George Sperber e Paulo Astor Soethe. São Paulo: Edições Loyola, 2002.

HÖFFE, Otfried. Derecho intercultural. Traducción de Rafael Sevilla. Barcelona: Gedisa, 2000.

JULIANO, Dolores. Universal/particular. Un falso dilema. In: BAYARDO, Rubens; LACARRIEU, Mónica (Comp.). Globalización e identidad cultural. 2. ed. Buenos Aires: Ediciones Ciccus, 1998. 
KYMLICKA, Will. Ciudadanía multicultural. Una teoría liberal de los derechos de las minorías. Traducción de Carme Castells Auleda. Barcelona: Paidós, 1996.

KYMLICKA, Will. Estados, naciones y culturas. Traducido y adptado por Juan Jesús Mora. Córdoba: Editorial Almuzara, 2004.

KYMLICKA, Will. La política vernácula. Nacionalismo, multiculturalismo y cidadania. Traducción de Tomás Fernandéz Aúz y Beatriz Eguibar. Barcelona: Paidós, 2003.

LA FUENTE, Oscar Pérez de. La polémica liberal comunitarista.

Paisajes después de la batalla. Cuadernos "Bartolomé de las Casas" 35. Madrid: Dykinson, 2005.

LA FUENTE, Oscar Pérez de. Pluralismo cultural y derechos de las minorías. Una aproximación iusfilosófica. Madrid: Dykinson, 2005.

LAPORTA, Francisco J. Comunitarismo e nacionalismo. In: Doxa. Cuadernos de Filosofía del Derecho. Alicante: Universidad de Alicante; Biblioteca Digital Miguel Cervantes, n. 17-18, p. 53-68, 1995.

LÓPEZ, Eduardo Riveira. Las paradojas del comunitarismo. In: Doxa. Cuadernos de Filosofía del Derecho. Alicante: Universidad de Alicante; Biblioteca Digital Miguel Cervantes, n. 17-18, p. 95-115, 1995.

MACINTYRE, Alasdair. Depois da virtude. Um ensaio em teoria moral. Tradução de Jussara Simões. Bauru, SP: EDUSC, 2001.

MACINTYRE, Alasdair. Justiça de quem? Qual racionalidade? Tradução de Marcelo Pimenta Marques. 2. ed. São Paulo: Loyola, 2001.

MALDONADO, Daniel Bonilla. La constitución multicultural. Bogotá: Siglo del Hombre; Pontificia Universidad Javeriana; Universidad de los Andes, 2006.

MARTÍNEZ-PUJALTE, Antonio-Luis. Derechos humanos e identidad cultural. Una posible conciliación entre interculturalidad y universalidad. In: Persona y Derecho. Pamplona: Universidad de Navarra, n. 38, 1998.

MASSINI CORREAS, Carlos Ignácio. Liberalismo, comunitarismo, realismo: en busca de la tercera via. In: Sapientia. Buenos Aires. v. 56. n. 210, p. $549-564$. 
MIGUEL, Alfonso Ruiz. Derechos humanos y comunitarismo. Aproximación a un debate. In: Doxa. Cuadernos de Filosofía del Derecho. Alicante: Universidad de Alicante; Biblioteca Digital Miguel Cervantes, n. 12, p. 95-114, 1992.

MONTIEL, Edgar. A nova ordem simbólica: a diversidade cultural na era da globalização. In: SIDEKUM, Antônio (Org.). Alteridade e multiculturalismo. Ijuí: Unijuí, 2003.

OLIVÉ, León. Multiculturalismo y pluralismo. México: Paidós, 1999.

OLSEN, Teresa Cristina Tschepokaitis. Uma introdução ao debate acerca da fundamentação dos direitos humanos: liberalismo versus comunitarismo. Revista Direito, Estado e Sociedade. v. 9, n. 24, p. 112136, jan./jun. 2004.

PAREKH, Bhikhu. Repensando el multiculturalismo. Diversidad cultural y teoría política. Traducción de Sandra Chaparro. Madrid: Istmo, 2000.

PEDREIRA, Elena Beltrán. Diversidad y deberes cívicos: liberalismo, ciudadanía y multiculturalismo. In: DÍAZ, Elías; COLOMER, José Luis. Estado, justicia, derechos. Madrid: Alianza Editorial, 2002.

PINILLA, Julio Seoane. Comunitarismo. Multiculturalismo. Un comentario. In: Doxa. Cuadernos de Filosofía del Derecho. Alicante: Universidad de Alicante; Biblioteca Digital Miguel Cervantes, n. 20, p. 377-390, 1997.

RAWLS, John. O liberalismo político. Tradução de Dinah de Abreu Azevedo. 2. ed. São Paulo: Ática, 2000.

RAZ, Joseph. La ética en el ámbito público. Traducción de Maria Luz Melon. Barcelona: Gedisa, 2001.

RUIZ, Ramón. Liberalismo y comunitarismo: dos perspectivas antagónicas del fenómeno multicultural. In: RUIZ, Ramón et al. (Ed.). Derechos fundamentales, valores y multiculturalismo. Madrid: Dykinson, 2005.

RUIZ-GALVEZ, Maria Encarnación Fernández. Del universalismo abstracto a la universalidad concreta. In: Persona y Derecho. Pamplona: Universidad de Navarra, n. 41, 1999. 
RUIZ-GALVEZ, Maria Encarnación Fernández. Derechos humanos: ¿Yuxtaposición o integración? In: Anuario de Filosofía del Derecho. Madrid: Nueva Época, n. IX, 1997.

SANCHÉS-CÁMARA, Ignácio. El comunitarismo y la universalidad de los derechos humanos. In: Persona y Derecho. Pamplona: Universidad de Navarra, n. 38, 1998.

SANCHÉS-CÁMARA, Ignácio. Estado laico y sociedad multicultural. In: Sociedad multicultural y derechos fundamentales. Madrid: Consejo General de Poder Judicial, 2007.

SANDEL, Michael. O liberalismo e los limites da justicia. Lisbos: Calouste Gulbenkian, 2005.

SANTOS, Boaventura de Sousa. Por uma concepção multicultural dos direitos humanos. In: SANTOS, Boaventura de Sousa (Org.). Reconhecer para libertar: os caminhos do cosmopolitismo multicultural. Rio de Janeiro: Civilização Brasileira, 2003.

SEMPRINI, Andrea. Multiculturalismo. Tradução de Laureano Pelegrin. Bauru: EDUSC, 1999.

SORIANO, Ramón. Interculturalismo. Entre liberalismo y comunitarismo. Córdoba: Almuzara, 2004.

TAYLOR, Charles. A política de reconhecimento. In: TAYLOR, Charles et al. Multiculturalismo - examinando a política de reconhecimento. Lisboa: Piaget, 1998.

TAYLOR, Charles. Argumentos filosóficos. Tradução de Adail Ubirajara Sobral. São Paulo: Edições Loyola, 2000.

TAYLOR, Charles. As fontes do self. a construção da identidade moderna. Tradução de Adail Ubirajara Sobral e Dinah de Abreu Azevedo. São Paulo: Edições Loyola, 1997.

TORRE, Giuseppe Dalla. La multiculturalità come dato di fatto e come programma etico-politico. In: TORRE, Giuseppe Dalla; D’AGOSTINO, Francesco (Org.). La cittadinanza. Problemi e dinamiche in una società pluralística. Torino: G. Giappichelli Editore, 2000.

TOURAINE, Alain. Poderemos viver juntos? iguais e diferentes. Tradução de Jaime A. Clasen e Ephairaim F. Alves. Petrópolis: Vozes, 1999. 
VITALE, Ermanno. Liberalismo e multiculturalismo. Una sfida per il pensiero democratico. Roma-Bari: Laterza, 2000.

WALZER, Michael. Comentário ao ensaio de Taylor. In: TAYLOR, Charles et al. Multiculturalismo - examinando a política de reconhecimento. Lisboa: Piaget, 1998.

WALZER, Michael. Esferas de justiça. Uma defesa do pluralismo e da igualdade. Tradução de Jussara Simões. São Paulo: Martins Fontes, 2003. 